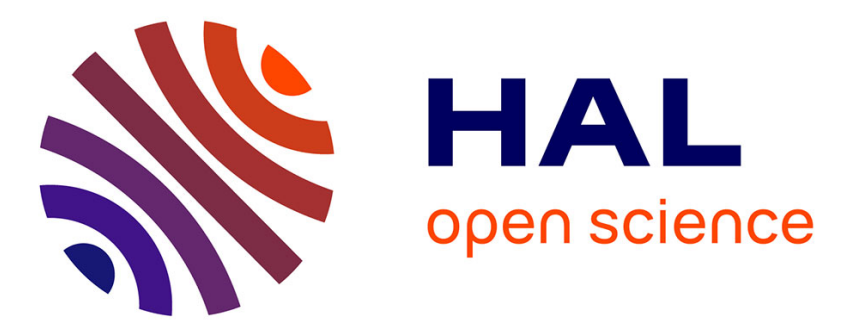

\title{
Genetic parameters of growth, straightness and wood chemistry traits in Pinus pinaster
}

Lepoittevin, Rousseau, Guillemin, Gauvrit, Besson, Hubert, Silva Perez, Harvengt, Christophe Plomion

\section{To cite this version:}

Lepoittevin, Rousseau, Guillemin, Gauvrit, Besson, et al.. Genetic parameters of growth, straightness and wood chemistry traits in Pinus pinaster. Annals of Forest Science, 2011, 68 (4), pp.873-884. 10.1007/s13595-011-0084-0 . hal-00930817

\section{HAL Id: hal-00930817 https://hal.science/hal-00930817}

Submitted on 1 Jan 2011

HAL is a multi-disciplinary open access archive for the deposit and dissemination of scientific research documents, whether they are published or not. The documents may come from teaching and research institutions in France or abroad, or from public or private research centers.
L'archive ouverte pluridisciplinaire HAL, est destinée au dépôt et à la diffusion de documents scientifiques de niveau recherche, publiés ou non, émanant des établissements d'enseignement et de recherche français ou étrangers, des laboratoires publics ou privés.

$$
\text { Copyright }
$$




\title{
Genetic parameters of growth, straightness and wood chemistry traits in Pinus pinaster
}

\author{
Camille Lepoittevin • Jean-Pierre Rousseau • Audrey Guillemin • \\ Christophe Gauvrit • François Besson • François Hubert • Denilson da Silva Perez • \\ Luc Harvengt • Christophe Plomion
}

Received: 20 May 2010 / Accepted: 20 January 2011 /Published online: 15 June 2011

(C) INRA and Springer Science+Business Media B.V. 2011

\begin{abstract}
- Introduction Tree breeding is giving an increasing attention to wood properties in order to better fit the requirements of the saw, board, pulp and paper industries. In particular, it has been reported that lignin and cellulose content display moderate to high heritabilities making them prime candidates for genetic improvement of wood chemistry. Moreover, these traits have been shown to be negatively correlated at both phenotypic and genetic levels. However, they have generally been evaluated against a narrow genetic background, and little is known about their correlations with mandatory selection criteria such as growth and straightness.
\end{abstract}

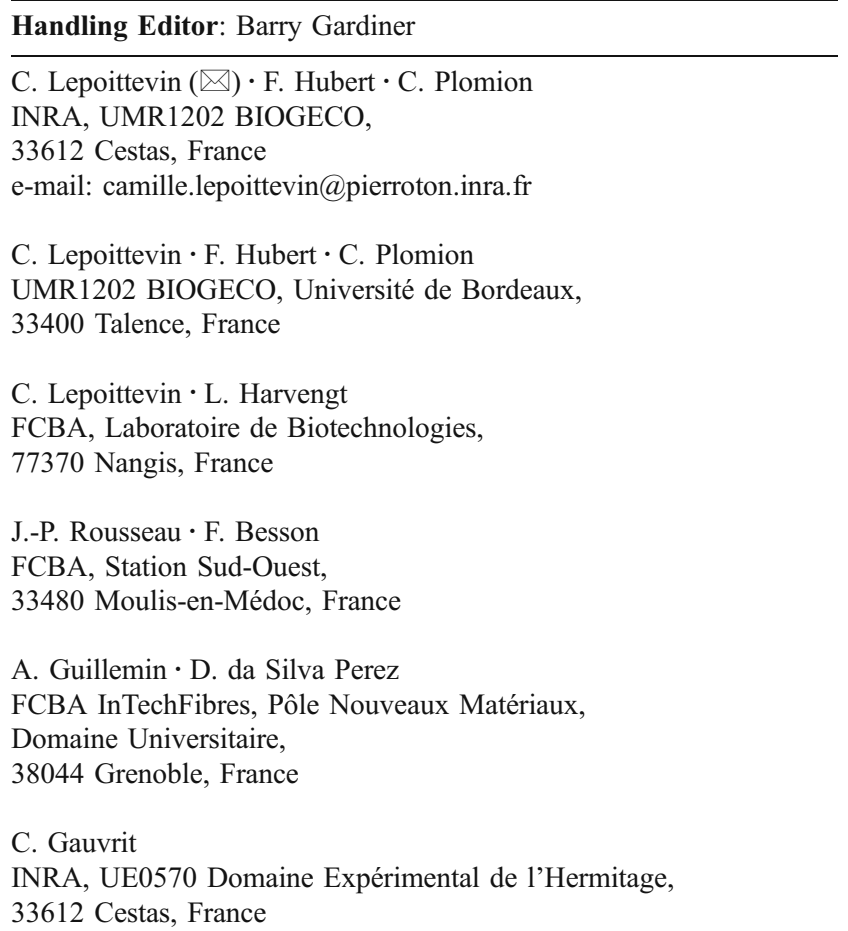

- Materials and methods In this study, we first investigated the performance of near-infrared (NIR) spectroscopy combined with a non-destructive sampling method to assess chemical properties of wood in maritime pine. We afterwards estimated genetic parameters of growth, stem form and wood chemistry traits across a large genetic background in a progeny trial and clonally replicated progenies.

- Results Our results showed that removal of extractives prior to NIR spectra acquisition is highly recommended for achieving high accuracy in NIRS-PLSR prediction for wood chemistry traits in maritime pine.

We further observed moderate heritabilities $(0.15-0.55)$ for the studied traits. Wood chemistry traits were genetically inter-correlated (e.g., negatively between lignin and cellulose), whereas correlations with growth were not significant, indicating that growth and chemical properties could be improved independently.

Keywords Pinus pinaster . Wood chemical properties . Growth · Heritability - Genetic correlations · Additivity . Dominance $\cdot$ Epistasis $\cdot$ Wood sampling

\section{Introduction}

Lignin and cellulose are major components of wood, and the most abundant biopolymers on Earth. Lignin accumulates in the secondary cell wall of xylem cells, playing a key role in sap conduction, mechanical support and biotic and abiotic stress resistance (Plomion et al. 2001). Although lignin is used as a fuel for bio-power generation, it is undesirable in the conversion of wood into pulp since it causes discoloration and reduces paper brightness upon thermal or light exposure (Chiang et al. 1988). Its removal 
is a major step in the papermaking process for "chemical pulps", which consumes large quantities of energy and chemicals. In addition, lignin acts as cement between fibres and is also responsible for the high energy consumption in thermo-mechanical pulp production due to energy required to separate fibres. Conversely, cellulose content is favourably correlated with pulp yield (Wallis et al. 1996; Kube and Raymond 2002). Breeders are, therefore, seeking ways to increase the cellulose to lignin ratio. Previous studies in various forest tree species showed that lignin and cellulose contents have moderate heritabilities and are strongly negatively correlated at both phenotypic and genetic levels (Baillères et al. 2002; Pot et al. 2002; Sykes et al. 2006; Da Silva Perez et al. 2007), highlighting the possibility of obtaining significant genetic gains for the cellulose to lignin content ratio by classical breeding methods. However, wood chemistry traits have generally been evaluated against a narrow genetic background such as diallel and factorial mating designs involving a low number of genotypes. Moreover, little is known about their correlations with mandatory selection criteria such as growth and straightness, or with other end-use properties such as wood density, modulus of elasticity or fibre-related traits (Pot et al. 2002; Da Silva Perez et al. 2007). Recent studies involving transgenic poplars and radiata pines suggest that the capacity for lignin reduction is limited: lignin contents reduced by less than $10 \%$ do not appreciably change tree growth characteristics (Pilate et al. 2002; Wagner et al. 2009; Voelker et al. 2010), whereas reductions in lignin content by about $20 \%$ can dramatically affect productivity (Leple et al. 2007; Wagner et al. 2009; Voelker et al. 2010). Considering the low natural variability of lignin content in conifer species ( $3-4 \%$ in Costa e Silva et al. 1998; Pot et al. 2002; Hannrup et al. 2004), it can be hypothesized that breeding for low lignin content would not impact growth performance. Breeding for a slight decrease in lignin content, however, seems worthwhile given the volume of wood processed each year by the pulp industry (Peter et al. 2007).

In the last decade, wood phenotyping has been enhanced by the development of indirect tools such as the pilodyn penetrometer and the resistograph for measuring wood density (Wang et al. 1999; Bouffier et al. 2008), or nearinfrared spectroscopy (NIRS) for predicting the wood chemical and physical properties of a large number of samples by fast optical measurements (reviewed by Tsuchikawa 2007). NIRS has been widely used in fields such as food, agriculture, pharmaceutical or chemical industries. However, its application in wood and paper science is recent (most of the results have been published in the 1990s) and appears as a cost- and time-efficient alternative to wet chemistry methods. On the other hand, due to the complexity of NIR spectra, all measurements are calibration dependent, which complicates wide-spread application (Da Silva Perez et al. 2008).

In this study, we first investigate the performance of NIRS combined with a non-destructive sampling method to assess wood chemical properties in maritime pine (Pinus pinaster Ait.), the principal conifer species used for largescale reforestation in south-western Europe. We then estimate the genetic parameters of growth, stem form and wood chemistry traits using a progeny trial with clonally replicated individual offspring derived from control crosses, with the aim of assessing the relative importance of additive, dominance and epistatic effects for these traits in a material representing a broad genetic background. Finally, we estimate the phenotypic and genetic correlations between these traits and discuss the breeding opportunities for wood chemistry traits.

\section{Materials and methods}

\subsection{Plant material}

Two experimental trials, Hermitage (trial number 2-44-17) and Vaquey (trial number 33802), located in the Aquitaine region (south-western France) were examined (Table 1). The Hermitage trial was described in earlier publications where genetic parameters for a series of traits related to growth and density have been studied (Bouffier et al. 2008; Bouffier et al. 2009). Briefly, Hermitage is a 31 -year-old progeny trial of plus-trees phenotypically selected in the Aquitaine forest for overall good growth and form. This material is commonly referred as the first generation breeding population $\left(G_{0}\right)$. A total of $261 G_{0}$ mother trees were crossed with a pollen mix collected from 28 unrelated $G_{0}$ trees, resulting in 8,667 individuals distributed in families of 12 to 36 half-sibs. This trial was installed on a humid sandy podzol moor site of low fertility (which represents $80 \%$ of the forested area in the Aquitaine region), using randomized complete block design with three, six or nine tree-row plots per family per block. Vaquey is a 13-year-old clonal trial of 189 trees from the second-generation breeding population $\left(G_{1}\right)$ which were individually selected within full-sib progenies of $77 G_{0}$ trees, based on their genetic value for growth and stem straightness. These $189 G_{1}$ clones belonged to 78 full-sib families (some $G_{0}$ parents were used in several crosses) and were replicated three to five times, leading to a total number of 892 trees. This trial was established on a humic loamy clay soil using fully randomized single-tree plots. No field blocks were a priori defined. Material from this trial has been previously used for developing NIRS calibrations (Da Silva Perez et al. 2005), without any estimation of genetic parameters. These two trials will be referred as the 
Table 1 Description of trials and sampling procedure

\begin{tabular}{|c|c|c|c|}
\hline \multicolumn{2}{|l|}{ Trial } & Hermitage (HST) & Vaquey $(\mathrm{CT})$ \\
\hline \multicolumn{2}{|l|}{ Plantation year } & 1975 & 1987 \\
\hline \multicolumn{2}{|l|}{ Blocks } & 4 & 0 \\
\hline \multicolumn{2}{|l|}{ Trees per plot } & 3,6 or 9 & 1 \\
\hline \multicolumn{2}{|l|}{ Number of families or clones } & 261 families & 189 clones/78 families \\
\hline \multicolumn{2}{|l|}{ Number of trees } & 8,667 & 892 \\
\hline \multicolumn{2}{|l|}{ Seedlings } & Bare roots & Containers \\
\hline \multicolumn{2}{|l|}{ Plantation density } & $4 \times 1.1 \mathrm{~m}$ & $6 \times 6 \mathrm{~m}$ \\
\hline \multicolumn{2}{|l|}{ Soil } & Humid sandy podzol moor & Loamy clay soil \\
\hline \multicolumn{2}{|l|}{ Fertilisation } & No & No \\
\hline \multirow[t]{3}{*}{ Growth (Ht, Gir, Diam) } & Tree age (years) & 8 & 8 (Ht), 13 (Diam) \\
\hline & Number of families or clones & 261 & 189 clones/78 families \\
\hline & Number of trees & 8,667 & 892 \\
\hline \multirow[t]{3}{*}{ Form (Str) } & Tree age (years) & 8 & - \\
\hline & Number of families or clones & 261 & - \\
\hline & Number of trees & 8,667 & - \\
\hline \multirow{4}{*}{$\begin{array}{l}\text { Wood chemistry traits (Ext, } \\
\text { Lign, Cell, Hemi, Mann, } \\
\text { Gal, Xyl) }\end{array}$} & Tree age (years) & 31 & 13 \\
\hline & Number of families or clones & $105^{\mathrm{a}}$ & 189 clones/78 families \\
\hline & Number of trees & 993 & 892 \\
\hline & Type of sample & $\begin{array}{l}\text { Shavings from } \\
\text { standing trees }\end{array}$ & Discs \\
\hline
\end{tabular}

${ }^{\text {a }}$ Families for which more than nine trees were still available in 2006, after two systematic thinning where half of the trees were removed in each family

Half-Sib Trial for Hermitage (HST), and the Clonal Trial for Vaquey (CT).

\subsection{Data measurement}

Table 1 describes the sampling procedure and the traits that have been measured on both trials. All the trees from the two trials were measured for growth traits, i.e. total height $(\mathrm{Ht})$ and girth at $1.3 \mathrm{~m}$ (Gir) at 8 years for the HST, and $\mathrm{Ht}$ at 8 years and diameter at $1.3 \mathrm{~m}$ (Diam) at 13 years for the CT. Trees from the HST were also evaluated for stem deviation from verticality (Str) at 8 years (the deflection from to the vertical was measured at $1 \mathrm{~m}$ ).

Chemical characterization of the samples was conducted separately for the two tests by NIRS. For the HST, the sampling was carried out at 31 years of age on 993 standing trees representing 105 different half-sib families, with seven to 12 trees per family. We collected shavings by drilling a hole of $2 \mathrm{~cm}$ in diameter and $5 \mathrm{~cm}$ in depth into the tree at breast height $(1.3 \mathrm{~m})$. The shavings were dried for $24 \mathrm{~h}$ at $60^{\circ} \mathrm{C}$, ground in a SM-100 three-knife mill (Retsch, Haan, Germany) and sieved.

Near-infrared spectra acquisition was then carried out on the 40-60 mesh sawdust fraction using a MPA spectrometer with an integration sphere (Bruker Optics, Ettlingen,
Germany). NIRS-partial least square (NIRS-PLSR) calibrations were developed using a subset of 98 samples measured for (1) extractives content (Ext) using an automatic SoxTec extractor (Foss, Hillrod, Denmark) and an acetone-water extraction sequence (Da Silva Perez et al. 2005), (2) lignin content (Lign) based on the Klason method (Schwanninger and Hinterstoisser 2002) and (3) polysaccharides: cellulose (Cell) and hemicellulose (Hemi) contents calculated from the wood monosugars contents liberated by acidic hydrolysis and analysed by HPLC (Puls et al. 1995). The glucose content was entirely attributed to cellulose (and therefore not studied), although it is known that a small fraction of this monosugar also enters in the composition of hemicelluloses. For this later component, the proportions of monosugars (mannose (Mann), galactose (Gal) and xylose (Xyl) content) can be variable and were included as wood chemistry traits. PLSR was performed according to Workman et al. (1996) and Martens and Naes (1989) using the OPUS Quant software (Bruker Optics).

NIRS-PLSR evaluation in the CT for Klason lignin, cellulose, hemicellulose, mannose, galactose and xylose contents at 13 years was carried out on extractive-free sawdust obtained from whole discs collected at breast height $(1.3 \mathrm{~m})$ as described in Da Silva Perez et al. (2005). 
For both trials, the quality of NIRS-PLSR models was assessed using the rank (number of PLS eigen vectors used for the regression) and cross-validation results, i.e. coefficient of determination $\left(R^{2}\right)$, and root mean square of error prediction (RMSECV) (Burns and Ciurczak 2008).

\subsection{Statistical models for genetic parameter estimation}

The individual-tree model was used to partition the phenotypic value of each tree in its genetic and environmental components.

The following model was used for the HST:

$y=X b+Z_{1} a+Z_{2} v+e$

where $y$ is a vector of observations on a trait, $b$ is a vector of fixed block effects, $a$ is a vector of random genetic effects of individual genotypes, $v$ is a vector of random plot effects (block $\times$ half-sib family interactions), $e$ is the vector of residuals, $X, Z_{1}$ and $Z_{1}$ are the incidence matrices linking observations to the effects. The random effects in model (1) were assumed to follow a normal distribution with means and variances defined by:

$$
\left[\begin{array}{l}
a \\
v \\
e
\end{array}\right] \sim N\left(\left[\begin{array}{l}
0 \\
0 \\
0
\end{array}\right],\left[\begin{array}{ccc}
A \sigma_{a}^{2} & 0 & 0 \\
0 & I \sigma_{v}^{2} & 0 \\
0 & 0 & I \sigma_{e}^{2}
\end{array}\right]\right)
$$

where 0 is a null matrix; $A$ is the additive genetic relationship matrix (computed from a pedigree that takes into account all the relationships among individual genotypes); $I$ is the identity matrix, $\sigma_{a}^{2}$ is the additive genetic variance, $\sigma_{v}^{2}$ the plot variance, and $\sigma_{e}^{2}$ is the residual variance. As the variances are assumed to be independent, the phenotypic variance $\sigma_{P}^{2}$ is defined as:

$\widehat{\sigma_{P}^{2}}=\widehat{\sigma_{a}^{2}}+\widehat{\sigma_{v}^{2}}+\widehat{\sigma_{e}^{2}}$

For the CT, two different models, named "full model" and "simplified model" were used. The full model is as follows:

$y=Z_{1} a+Z_{2} f+Z_{3} c+e$

where $a$ and $e$ are defined as above, $f$ is a vector of random full-sib family effects, $c$ is a vector of random effect of clones within full-sib families, $Z_{1}, Z_{2}$ and $Z_{3}$ are the incidence matrices linking the observations in $y$ to the effects in $a, f$ and $c$, respectively. The random effects in the model defined in Eq. 4 were assumed to follow normal distributions with means and variances defined by:

$$
\left[\begin{array}{l}
a \\
f \\
c \\
e
\end{array}\right] \sim N\left(\left[\begin{array}{l}
0 \\
0 \\
0 \\
0
\end{array}\right],\left[\begin{array}{cccc}
A \sigma_{a}^{2} & 0 & 0 & 0 \\
0 & I \sigma_{f}^{2} & 0 & 0 \\
0 & 0 & I \sigma_{c}^{2} & 0 \\
0 & 0 & 0 & I \sigma_{e}^{2}
\end{array}\right]\right)
$$

where $0, I, \sigma_{a}^{2}$ and $\sigma_{e}^{2}$ are defined as above (observations on different ramets of a clone were treated as repeated measurements on a single genotype, therefore $A$ is the matrix of relationships among individual genotypes as mentioned before); $\sigma_{f}^{2}$ is the non-additive genetic variance among full-sib families, and $\sigma_{c}^{2}$ is the non-additive variance among clones within full-sib families. This full model was used after excluding from the dataset the families with only one genotype, as they do not allow the estimation of dominance effects (Costa e Silva et al. 2009). Thus the full model was fitted for 36 families representing 143 clones and 705 phenotypes out of the 892 trees. The phenotypic variance $\sigma_{P}^{2}$, the total genetic variance $\sigma_{G}^{2}$, the dominance genetic variance $\sigma_{D}^{2}$ and the epistatic genetic variance $\sigma_{I}^{2}$ were defined as follows:

$\widehat{\sigma_{P}^{2}}=\widehat{\sigma_{a}^{2}}+\widehat{\sigma_{f}^{2}}+\widehat{\sigma_{c}^{2}}+\widehat{\sigma_{e}^{2}}$

$\widehat{\sigma_{G}^{2}}=\widehat{\sigma_{a}^{2}}+\widehat{\sigma_{f}^{2}}+\widehat{\sigma_{c}^{2}}=\widehat{\sigma_{a}^{2}}+\widehat{\sigma_{D}^{2}}+\widehat{\sigma_{I}^{2}}$

$\widehat{\sigma_{D}^{2}}=4 \times \widehat{\sigma_{f}^{2}}$

$\widehat{\sigma_{I}^{2}}=\widehat{\sigma_{c}^{2}}-3 \times \widehat{\sigma_{f}^{2}}$

For Eqs. 8 and 9, we assumed a large, random mating parental population with diploid inheritance and near linkage equilibrium at gene loci affecting the observed traits (Comstock et al. 1958; Foster and Shaw 1988). As $\widehat{\sigma_{a}^{2}}$ and $\widehat{\sigma_{f}^{2}}$ contain portions of epistasis with successively decreasing contributions of interactions involving larger groups of loci, the unbiased estimation of additive and dominance variances assumes that higher-order interloci interactions only represent a small portion of the total epistasis (Mullin and Park 1992; Wu 1996; Costa e Silva et al. 2004). Similarly, interactions involving groups of more than two or three loci are assumed in Eq. 9, since $\widehat{\sigma_{I}^{2}}$ contains only a fraction of the total epistasis with a major contribution of high-order interactions. In addition, nongenetic effects introduced by cloning ("C effects") (Foster and Shaw 1988; Costa e Silva et al. 2004) were assumed to be negligible or absent.

The simplified model entailed in dropping the family and clonal effects from the full model (4) described above, so that we could use the total dataset to estimate the variance components (i.e. 78 families, 189 genotypes and 892 phenotypes). In this model, the family structure is ignored although the kinship is accounted for. Dominance and epistatic genetic effects can no longer be estimated, 
therefore only the total genetic variance $\widehat{\sigma_{G}^{2}}$ was estimated as described in Eq. 7.

The estimates of the fixed and random effects were obtained by solving Henderson's mixed model equations (Henderson 1975) using the average information REML algorithm (Gilmour et al. 1995) implemented in the ASReml v2.0 software (Gilmour et al. 2006). Wald tests as implemented in ASReml (Gilmour et al. 2006) and likelihood ratio tests were used to assess the statistical significance of the fixed and random effects, respectively.

Analyses were performed for each trait separately. Estimates of phenotypic, total genetic and additive genetic coefficients of variation $\left(\widehat{\mathrm{CV}}_{P}, \widehat{\mathrm{CV}}_{G}\right.$ and $\left.\widehat{\mathrm{CV}}_{A}\right)$ as well as broad- and narrow-sense heritabilities $\left(\widehat{h_{\mathrm{bs}}^{2}}\right.$ and $\left.\widehat{h_{\mathrm{ns}}^{2}}\right)$ were defined as follows:

$$
\begin{aligned}
& \widehat{\mathrm{CV}_{P}}=\frac{\widehat{\sigma_{P}}}{\overline{\bar{X}}} ; \widehat{\mathrm{CV}_{G}}=\frac{\widehat{\sigma_{G}}}{\bar{X}} ; \widehat{\mathrm{CV}_{A}}=\frac{\widehat{\sigma_{a}}}{\bar{X}} \\
& \widehat{h_{\mathrm{bs}}^{2}}=\frac{\widehat{\sigma_{G}^{2}}}{\widehat{\sigma_{P}^{2}}} ; \widehat{h_{\mathrm{ns}}^{2}}=\frac{\widehat{\sigma_{a}^{2}}}{\widehat{\sigma_{P}^{2}}}
\end{aligned}
$$

where $\bar{X}$ is the mean of the studied trait for the trial considered.

The estimated phenotypic $\left(\widehat{r_{P}}\right)$, total genetic $\left(\widehat{r_{G}}\right)$, and additive genetic $\left(\widehat{r_{A}}\right)$ correlations between traits were obtained using bivariate extensions of the models previously described, for each pair of traits and each trial. They were evaluated as follows:

$$
\widehat{r_{P}}=\frac{\widehat{\operatorname{Cov}_{P}}(x, y)}{\sqrt{\sigma_{P_{x}}^{2}+\widehat{\sigma_{P_{y}}^{2}}}} \quad \widehat{r_{G}}=\frac{\widehat{\operatorname{Cov}}_{G}(x, y)}{\sqrt{\widehat{\sigma_{G_{x}}^{2}}+\widehat{\sigma_{G_{y}}^{2}}}} \quad \widehat{r_{A}}=\frac{\widehat{\operatorname{Cov}_{A}}(x, y)}{\sqrt{\widehat{\sigma_{a_{x}}^{2}}+\widehat{\sigma_{a_{y}}^{2}}}}
$$

where $\widehat{\operatorname{Cov}}_{P}(x, y), \widehat{\operatorname{Cov}}_{G}(x, y)$ and $\widehat{\operatorname{Cov}}_{A}(x, y)$ are the phenotypic, genetic and additive genetic covariances between traits $x$ and $y$, respectively. For the $\mathrm{CT}$, the simplified model was used to estimate a total genetic correlations $\left(\widehat{r_{G}}\right)$, including additive, dominance and epistatic effects. Approximate standard errors for estimated variances, heritabilities and correlation coefficients were calculated with ASReml using a standard Taylor series expansion (Sorensen and Gianola 2002; Gilmour et al. 2006).

Expected genetic gains were estimated independently for each trait by dividing the expected response $(R)$ by the mean of the trait considered and expressed as a percentage. $R$ was calculated for individual selection according to the following formula:

$R=i \times \widehat{\sigma_{P}} \times \widehat{h_{\mathrm{ns}}^{2}}$

with

$\boldsymbol{i}$ selection intensity

$\widehat{\sigma_{P}}$ estimated phenotypic standard deviation

$\widehat{h_{\mathrm{ns}}^{2}}$ estimated narrow-sense heritability.
Expected genetic gains were only estimated for the HST, since our dataset did not allow accurate estimates of $\widehat{h_{\mathrm{ns}}^{2}}$ in the CT.

\section{Results}

\subsection{Near-infrared spectroscopy calibrations}

The performances of NIRS-PLSR calibrations for the prediction of chemical composition of maritime pine wood were assessed by cross validations and are shown in Table 2. Extractive, lignin, cellulose, mannose and galactose contents could be predicted by NIRS with a quite good accuracy in one or both trials, with low RMSECV and coefficients of determination $\left(R^{2}\right)$ ranging from 0.70 to 0.96. The calibrations developed for the CT site generally performed better than those developed for the HST site, displaying higher $R^{2}$, lower rank and RMSECV. Calibrations showing a cross-validation $R^{2}$ below 0.7 (i.e. cellulose and mannose contents for the HST, and hemicellulose and xylose contents of both trials) were not used for genetic parameters estimation because of the low accuracy of their predictions.

\subsection{Variance components}

Estimates of variance components obtained from the analysis of the two trials are presented in Table 3. Growth and stem straightness showed moderate to high coefficients of phenotypic variation $\left(\widehat{C V}_{P}=15-25 \%\right.$ for growth and $54 \%$ for straightness), in agreement with previous results (Costa and Durel 1996; Pot et al. 2002). With the exception of Ext and Gal, $\widehat{C V}_{P}$ for wood chemistry traits were low $(<7 \%)$, consistent with most of the results reported in the literature (Costa e Silva et al. 1998; Pot et al. 2002; Hannrup et al. 2004). The fixed block effect and random plot effect in the HST were highly significant ( $p$ value of $<0.1 \%$ ) for all traits except for Lign, for which only the plot effect was significant. For both trials, $\widehat{\sigma_{a}^{2}}$ and $\widehat{\sigma_{G}^{2}}$ were highly significant with very low $p$ values $(<0.1 \%)$.

In the $\mathrm{CT}, \sigma_{f}^{2}$ was accurately estimated and much lower than $\widehat{\sigma_{a}^{2}}$ for $\mathrm{Ht}$, suggesting a low contribution of dominance effects on this trait. For Diam, both $\widehat{\sigma_{f}^{2}}$ and $\widehat{\sigma_{c}^{2}}$ were accurately estimated and again non-significant ( $p$ value of $>5 \%$ ) and much lower than $\widehat{\sigma_{a}^{2}}$, also indicating strong additive control. For the other traits, $\widehat{\sigma_{f}^{2}}$ and $\widehat{\sigma_{c}^{2}}$ were non-significant, with values similar to or greater than $\widehat{\sigma_{a}^{2}}$, and standard errors of the same magnitude as the estimates. In these cases, our dataset did not allow accurate estimates of non-additive variances, thus the simplified model was preferable to estimate heritabilities and correlations. 
Table 2 Cross-validation performances of the NIRS-PLSR calibrations for the prediction of wood chemical composition in the Hermitage (HST) and Vaquey $(\mathrm{CT})$ trials

\begin{tabular}{|c|c|c|c|c|c|c|}
\hline \multirow[t]{2}{*}{ Trait } & \multirow[t]{2}{*}{ Trial } & \multicolumn{2}{|c|}{ Range (\%) } & \multirow[t]{2}{*}{ Rank } & \multicolumn{2}{|c|}{ Cross validation } \\
\hline & & Min & $\operatorname{Max}$ & & $R^{2}$ & RMSECV (\%) \\
\hline Ext & Hermitage & 3.3 & 10.3 & 4 & 0.70 & 0.76 \\
\hline \multirow[t]{2}{*}{ Lign } & Hermitage & 21.7 & 30.6 & 4 & 0.91 & 0.40 \\
\hline & Vaquey & 25.8 & 32.7 & 3 & 0.96 & 0.40 \\
\hline \multirow[t]{2}{*}{ Cell } & Hermitage & 36.8 & 47.4 & 3 & 0.53 & 1.51 \\
\hline & Vaquey & 39.9 & 51.1 & 2 & 0.92 & 0.80 \\
\hline \multirow[t]{2}{*}{ Hemi } & Hermitage & 20.1 & 28.2 & 8 & 0.34 & 1.22 \\
\hline & Vaquey & 23.3 & 28.4 & 5 & 0.53 & 0.73 \\
\hline \multirow[t]{2}{*}{ Mann } & Hermitage & 8.6 & 13.8 & 7 & 0.60 & 0.62 \\
\hline & Vaquey & 14.5 & 20.0 & 1 & 0.87 & 0.55 \\
\hline \multirow[t]{2}{*}{ Gal } & Hermitage & 1.4 & 6.1 & 10 & 0.82 & 0.49 \\
\hline & Vaquey & 2.0 & 10.9 & 7 & 0.94 & 0.72 \\
\hline \multirow[t]{2}{*}{ Xyl } & Hermitage & 3.7 & 8.2 & 8 & 0.30 & 0.86 \\
\hline & Vaquey & 9.1 & 13.9 & 5 & 0.63 & 0.50 \\
\hline
\end{tabular}

Estimated broad-sense heritabilities in the CT were low to moderate, ranging from 0.17 to 0.23 for chemicalrelated traits and from 0.24 to 0.38 for growth. Narrowsense heritabilities estimated in the HST ranged from 0.15 to 0.55 , and were generally higher than broad-sense heritabilities estimated on the CT for the same traits using the full and simplified models (except Gir which was twice as low).

\subsection{Genetic correlations}

Estimated phenotypic and genetic correlations between traits are shown in Table 4 for the HST and Table 5 for the CT. In the HST, Ht and Gir were strongly correlated at the phenotypic and genetic levels $\left(\widehat{r_{P}}=0.82, \widehat{r_{A}}=0.86\right)$, as expected, but weakly correlated with stem straightness at the genetic level $\left(\widehat{r_{A}}=0.15\right.$ and 0.24 , respectively). In both trials, wood chemistry traits were significantly correlated, showing in most cases higher values for genetic than phenotypic correlations. The highest correlation observed was between Lign and Cell in the CT $\left(\widehat{r_{G}}=-0.98\right.$ with a standard error of 0.01 ). We did not observe any significant genetic correlation between growth and chemical-related traits, although the phenotypic correlations were generally significant in the HST.

\subsection{Expected genetic gains}

Expected genetic gains were estimated for a selection of the $5 \%$ best units in the HST (Table 6). Although moderate to high genetic gains can be expected for most of the traits $(8.51 \%$ to $39.98 \%)$, the expected genetic gain was very low for lignin content $(1.51 \%)$.

\section{Discussion}

\subsection{Rapid wood-quality assessment techniques}

A prerequisite of a tree-breeding programme focusing on wood quality is the ability to measure whole-tree properties, which often implies the destructive sampling of discs to provide a bulk sample that represents the whole tree. Destructive sampling is extremely time-consuming and, owing to practical constraints, the number of trees that can be sampled is limited. An alternative to destructive sampling is to take an increment core or, as done in this study for the HST, to collect shavings by drilling a hole in the stem of a standing tree, and assume that the results are indicative of the whole-tree properties. However, this assumption can lead to erroneous results; indeed, we know that wood chemical composition shows significant radial variations, with mature wood (corewood as defined by Burdon et al. 2004) containing more cellulose and less lignin than juvenile wood (Zobel and Sprague 1998). The proportions of mature wood and juvenile wood in the powder obtained from increment cores or drill shavings are different from the true proportions of a stem section, and thus do not represent the whole tree. To illustrate this sampling bias, Augusto and Bert (2005) showed that using increment cores for determining nutrient contents generally leads to significant underestimations of whole-tree values in sapwood and overestimations in heartwood. Since the error associated with the drill sampling method increases with the drilling depth, restricting the sampling to the last rings should reduce this bias, but with the drawback of measuring only mature wood properties on adult trees. According to micro-density profiles of the HST (data from Bouffier et al. 


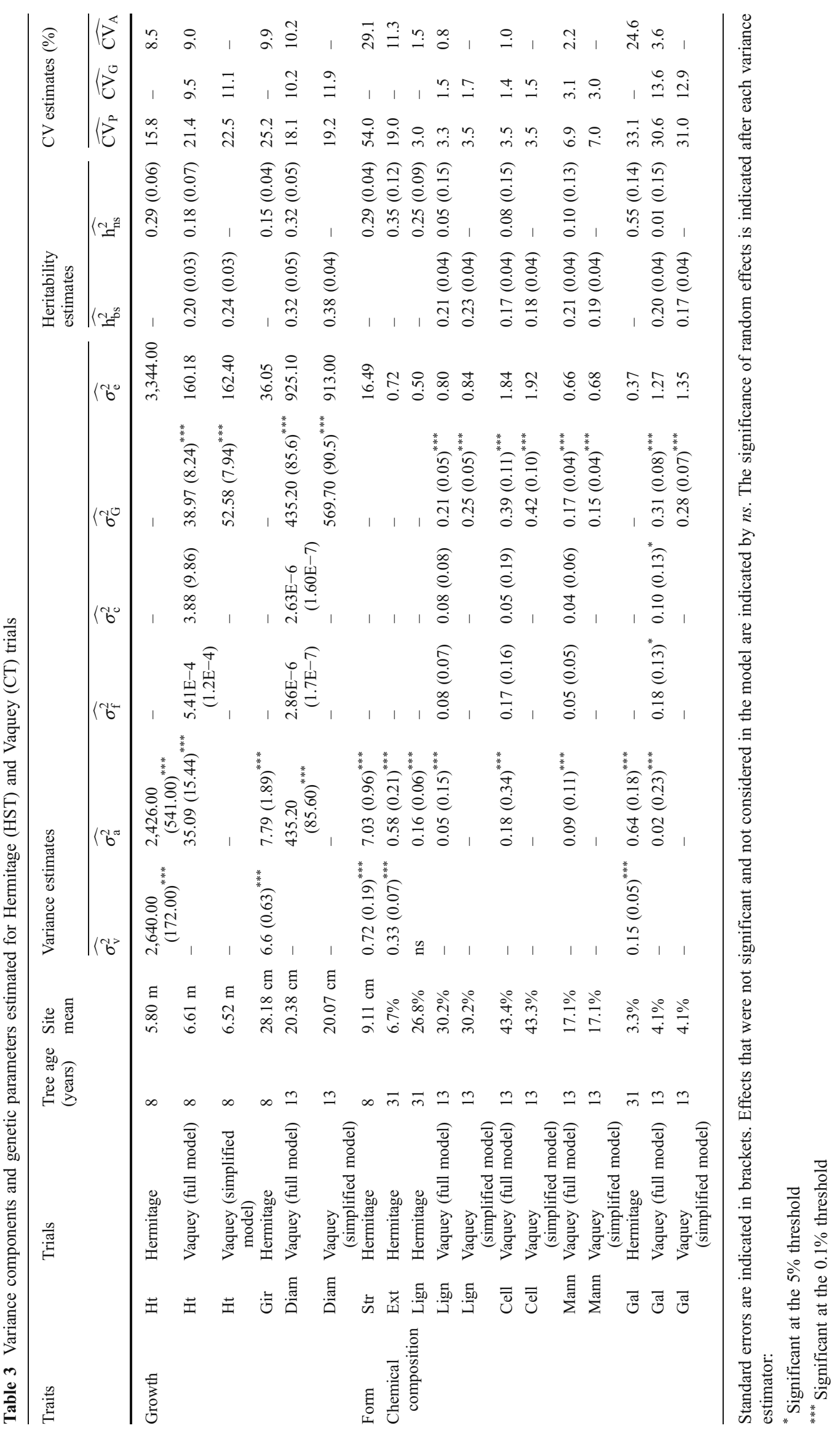


Table 4 Phenotypic and genetic correlations in the HST ( $\widehat{r_{P}}$ below and $\widehat{r_{A}}$ above the diagonal, respectively)

\begin{tabular}{lllllll}
\hline & Ht & Gir & Str & Ext & Lign & Gal \\
\hline Ht & - & $0.86(0.04)^{* * *}$ & $0.15(0.12)$ & $-0.46(0.26)$ & $-0.16(0.25)$ & $0.12(0.23)$ \\
Gir & $0.82(0.004)^{* * *}$ & - & $0.24(0.12)^{*}$ & $-0.10(0.28)$ & $-0.26(0.26)$ & $0.18(0.25)$ \\
Str & $0.27(0.01)^{* * *}$ & $0.36(0.01)^{* * *}$ & - & $-0.01(0.21)$ & $0.23(0.19)$ & $0.20(0.17)$ \\
Ext & $0.09(0.04)^{*}$ & $0.14(0.03)^{* * *}$ & $0.10(0.03)^{* * *}$ & - & $-0.57(0.20)^{* *}$ & $-0.96(0.13)^{* * *}$ \\
Lign & $-0.26(0.03)^{* * *}$ & $-0.26(0.03)^{* * *}$ & $-0.02(0.03)$ & $-0.32(0.03)^{* * *}$ & - & $0.85(0.12)^{* * *}$ \\
Gal & $-0.19(0.04)^{* * *}$ & $-0.19(0.03)^{* * *}$ & $0.04(0.04)$ & $0.03(0.03)$ & $0.57(0.02)^{* * *}$ & - \\
\hline
\end{tabular}

Standard errors are indicated in brackets after each coefficient. The significance of random effects is indicated after each variance estimator:

* Significant at the $5 \%$ threshold

** Significant at the $1 \%$ threshold

*** Significant at the $0.1 \%$ threshold

2008), $5 \mathrm{~cm}$ deep drillings corresponded to nine (for fastgrowing trees) to 24 (for slow-growing trees) growth rings. Assuming a transition between juvenile and mature wood in maritime pine to occur around the 10th to the 12th growth ring (Zobel et al. 1972; Dumail et al. 1998), $\sim 75 \%$ of the samples should mainly contain mature wood. Even if we generally avoided the sampling bias due to radial effects, the number of rings sampled greatly varied depending on the trees, thus a bias due to different annual climatic conditions is not possible to exclude. To our knowledge, the only published study using drill shavings to estimate conifer-wood chemical properties concluded that this sampling method gave errors that were too large for practical purpose (Jones et al. 2008). These authors used young trees (13-year-old loblolly pines), drilled holes from the cambium to the pith, and obtained poor NIRS-PLSR calibrations. Our sampling method was quite different in the HST (holes were drilled mainly in mature outerwood) and gave rather good calibrations, especially for lignin content (RMSECV of $0.40 \%$ ).

NIRS analysis relies on developing a calibration that relates the NIR spectra of a large number of samples to their known chemical or physical properties. Once the calibration has been set, NIR spectra can be used to predict these properties with the advantages of minimal sample preparation, rapid acquisition times, non-contact and nondestructive spectral acquisition (So et al. 2004). In the present study, two different types of samples were used for NIR spectra acquisition: (1) raw sawdust for the HST samples with the idea to routinely apply this low-cost and time-saving method into breeding and (2) extractive-free sawdust for the CT samples. They led to different calibration performances, the latter giving higher NIRSPLSR prediction accuracy for all the analysed traits. Such a result has previously been reported for eucalypts, with the improvement of calibration models for lignin content and sugar monomer composition after elimination of wood extractives (Baillères et al. 2002; Da Silva Perez et al. 2008). To explain such difference these authors hypothesized that polyphenolic compounds of wood extracts alter the lignin absorption bands located in the same spectral zones. Despite this result, NIRS calibration for lignin content based on non-extracted powder was of high quality in the present study, as it provided good predictions (RMSECV of $0.40 \%$ ). However, this was not the case for cellulose and most of monosugar calibrations, which showed very low performance for the raw sawdust. Extractives are a complex group of cell wall and lumen

Table 5 Phenotypic and genetic correlations in the CT ( $\widehat{r_{P}}$ below and $\widehat{r_{G}}$ above the diagonal, respectively)

\begin{tabular}{llllll}
\hline & Diam & Lign & Cell & Mann & Gal \\
\hline Diam & - & $-0.007(0.13)$ & $-0.12(0.14)$ & $0.09(0.14)$ & $0.18(0.14)$ \\
Lign & $-0.04(0.04)$ & - & $-0.98(0.01)^{* * *}$ & $-0.87(0.05)^{* * *}$ & $0.64(0.08)^{* * *}$ \\
Cell & $-0.02(0.04)$ & $-0.94(0.004)^{* * *}$ & - & $0.89(0.06)^{* * *}$ & $-0.79(0.06)^{* * *}$ \\
Mann & $0.05(0.04)$ & $-0.66(0.02)^{* * *}$ & $0.49(0.03)^{* * *}$ & - & $-0.75(0.09)^{* * *}$ \\
Gal & $0.05(0.04)$ & $0.82(0.01)^{* * *}$ & $-0.86(0.01)^{* * *}$ & $-0.61(0.03)^{* * *}$ & - \\
\hline
\end{tabular}

Standard errors are indicated in brackets after each coefficient. The significance of random effects is indicated after each variance estimator:

*** Significant at the $0.1 \%$ threshold 
Table 6 Expected genetic gain for each trait considered independently for a selection of the $5 \%$ best individuals

\begin{tabular}{llc}
\hline Trait & Target & Expected genetic gain (\%) \\
\hline $\mathrm{Ht}$ & Increase & 11.15 \\
Gir & Increase & 8.51 \\
Str & Decrease & 20.18 \\
Ext & Decrease & 12.15 \\
Lign & Decrease & 1.51 \\
Gal & Decrease & 27.50 \\
\hline
\end{tabular}

Trait abbreviations are described in Section 2.2

chemicals mainly consisting of fats, fatty acids, fatty alcohols, phenols, terpenes, steroids, resin acids, waxes and many other minor organic compounds (Rowell 2005). Their interaction with cellulose and monosugar absorption bands is likely, although to our knowledge it has never been explicitly reported. The differences between calibrations based on raw or extractive-free sawdust could also be due to other factors such as the sampling age (CT was sampled at 13 years while the HST was sampled at 31 years). Sampling method (discs versus drill shavings) may also be involved, but this seems unlikely, as poor sugar calibrations have already been reported for young loblolly pine raw sawdust ground from discs, while lignin calibration performed well (Jones et al. 2008), or for young maritime pine raw sawdust ground from whole stems (data not shown). Actually, these technical issues for assessing cellulose content can be easily avoided provided that lignin content is accurately predicted, because lignin and cellulose contents are strongly negatively correlated at both phenotypic and genetic levels, as found in the CT $\left(\widehat{r_{P}}=-0.94\right.$ and $\widehat{r_{G}}=-0.98$, with standard errors of 0.004 and 0.01 , respectively). This cellulose-lignin balance has been largely studied in conifers (Chantre et al. 2002; Pot et al. 2002; Sewell et al. 2002; Pot et al. 2006; Da Silva Perez et al. 2007), and confirmed by transgenic studies in various plant species where a cross talk between both pathways has been suggested (Hu et al. 1999; Baucher et al. 2003; Park et al. 2004).

\subsection{Genetic effects and heritabilities}

Genetic variance among individuals is usually partitioned into additive and non-additive components, the latter being a global term including allelic interactions within loci (dominance) and interactions between genes at two or more loci (epistasis) (Falconer and Mackay 1996). Selection response for traits mainly controlled by non-additive effects is not predictable from parental performance and noncumulative over generations. Although they have been intensively studied in the last decades, contradictory results have been published for growth and stem form, showing either low (Foster and Shaw 1988; Kusnandar et al. 1998; Isik et al. 2003; Baltunis et al. 2007; Da Silva Perez et al. 2007) or moderate (Cotterill et al. 1987; Pot et al. 2002; Hannrup et al. 2004) non-additive control. This heterogeneity could be due to the low sample sizes in the diallel and factorial designs employed. While these mating schemes are useful for the partitioning of the genetic variance into its sub-components, they generally involve a low number of parents (the number of parents ranged from six to 38 in the above-mentioned studies). However, large samples are generally needed to accurately estimate non-additive genetic variances (Foster and Shaw 1988; Costa e Silva et al. 2004). Recently, Costa e Silva et al. (2004) provided an elegant model to estimate dominance and epistatic effects using clonally replicated progenies of eucalypts: with 153 full-sib families originating from 79 parents, they estimated that dominance and epistatic effects accounted for between $0 \%$ and $4 \%$ and $0.4 \%$ of the phenotypic variance in stem diameter and for $0 \%$ and $5 \%$ of the phenotypic variance for pilodyn penetration (an indirect measure of wood density), respectively. In the present study, using the same model but a lower number of parents and families (47 and 36, respectively), we showed that non-additive effects for $\mathrm{Ht}$ as well as dominance effects for Diam were accurately estimated and not significantly different from 0 . However, our experimental design did not allow to accurately estimate non-additive variances for wood chemistry traits, which again shows that large datasets are required to reduce the standard errors of these components to low values.

Interestingly, for the same traits, narrow-sense heritabilities $\left(h_{\mathrm{nS}}^{2}\right)$ estimated on the HST were generally higher than broadsense heritabilities $\left(h_{\mathrm{bs}}^{2}\right)$ estimated on the $\mathrm{CT}$, whereas the opposite was expected (or at least equality between both estimates). A first hypothesis is that the error variance in the CT is larger than in the HST, as it includes a component of the environmental variance due to the absence of blocks in the trial, thus $h_{\mathrm{bs}}^{2}$ may be underestimated. For example, when the block effect was omitted from model (1) in the HST, $h_{\mathrm{ns}}^{2}$ was underestimated by $\sim 10 \%$ for form and wood chemistry traits and not significantly different from 0 for growth, because error and plot variances were greatly inflated. This illustrates the importance of controlling for environmental effects in large forestry trials, and also shows that growth traits are more sensitive to micro environmental conditions than wood chemistry traits. A spatial analysis of the CT would certainly improve heritability estimates (unfortunately, spatial data were not available for this trial). A second hypothesis is that changes with radial position could also be partly responsible for heritability variations between both trials, as wood chemistry traits were measured at different ages: 13 versus 31 years old for the CT and the HST, 
respectively. This bias could even be amplified by our sampling method in the HST, as previously discussed. Costa and Durel (1996) and Danjon (1994) showed that heritability of growth-related traits increased with age in maritime pine, and wood density also seems to follow this trend (Bouffier et al. 2008; Gaspar et al. 2008). However, to our knowledge time-trend analysis of wood chemistry traits heritability has not yet been reported. Further analyses will be necessary to confirm or reject this hypothesis. A third hypothesis is that half-sib families in the HST included full-sib pairs of genotypes that were not accounted for in our pedigree matrix, leading to an over-estimation of $h_{\mathrm{ns}}^{2}$. Recently, Gaspar et al. (2009) showed using molecular markers that the coancestry coefficient of maritime pine open-pollinated families was 0.130 , instead of the 0.125 value usually assumed for half-sib families. This underestimation of offspring relationships did not dramatically change heritability estimates in the studied trial, but simulations showed that the presence of around $10 \%$ of full-sibs in half-sib families is enough to produce heritability overestimation by $\sim 10 \%$ (Gaspar et al. 2009). In our case, the progenies of the HST were not obtained by open pollination but by a controlled cross involving a pollen mix collected from 28 trees (i.e. a "polycross" trial), thus the family coancestry coefficient could be higher than that of open-pollinated families, resulting in significant bias in heritabilities. Only the genotyping of the half-sib families and their parents with highly polymorphic markers such as microsatellites, as in Gaspar et al. (2009), would allow quantification of this bias and allow more accurate variance estimates.

\subsection{Perspectives for breeding applications}

We observed low to moderate heritabilities for all the studied traits, and the expected genetic gains for mandatory traits of the maritime pine breeding programme (growth and stem form) were higher than that observed for lignin content. However, given the volume of wood processed each year by the pulp industry and its predicted increase, even slight modifications of wood chemistry trait performances would be of commercial value. Indeed, an increase in cellulose to lignin ratio would be advantageous in decreasing energy and chemical consumption (Rydholm 1965), as well as increasing pulp yield. A recent economic study on loblolly pine showed that a $4 \%$ decline in lignin content (from $29 \%$ to $25 \%$ after selection) could yield a $4 \%$ increase in mill profits, but the advantages of further decline were eroded substantially by the loss of mill biopower generation and the consequent need to purchase more power from the open market (Peter et al. 2007). Our study shows that a $\sim 1.5 \%$ decrease in lignin content could be achieved in one maritime pine breeding generation with a $5 \%$ selection rate, in agreement with previous findings (Pot et al. 2002; Da Silva Perez et al. 2007). This breeding programme is in its third generation of selection, therefore significant genetic gain can be expected by classical breeding. However, genetic gains per unit of time are inevitably slow because of the long generation time and the fact that many traits can only be scored at rotation age. Further analyses of wood chemistry traits are thus needed to assess the extent of age-age correlations and genotype-byenvironment interactions, to quantify better the trade-offs with other wood-quality-related traits or the relative importance of additive and non-additive effects in their genetic control. In this context, the sampling method and NIRS technique used in the present study may offer some advantages when compared with conventional destructive sampling and wet chemistry methods. This rapid assessment technique gives estimates with reasonable precision for lignin content, hence contributing to a reduction in measurement costs.

Acknowledgements We thank INRA Experimental Unit UE0570 and Thomas Sanchez from FCBA for collecting the samples. We also thank Pierre Gardère, Maëlys Kerdraon and Guillaume Kubinski for wood samples processing, and Laurent Bouffier, Pauline Garnier-Géré, Annie Raffin, Pierre Alazard, Barry Gardiner and two anonymous reviewers for their helpful comments on the manuscript and/or analyses. This research was supported by grants from Agence Nationale de la Recherche Genoplante (GenoQB, GNP05013C), from the European Union (GEMINI, QLRT-199900942) and from the Aquitaine Region. Phenotyping of the half-sib trial was performed at the GenoBois Facility of Pierroton (Cestas). C. Lepoittevin was supported by CIFRE contract between FCBA and INRA. F. Hubert was funded by the EVOLTREE Network of Excellence (http://www.evoltree.org).

\section{References}

Augusto L, Bert D (2005) Estimating stemwood nutrient concentration with an increment borer: a potential source of error. Forestry 78:451-455

Baillères H, Davrieus F, Pichavant FH (2002) Near infrared analysis as a tool for rapid screening of some major wood characteristics in a eucalyptus breeding program. Ann For Sci 59:479-490

Baltunis BS, Huber DA, White TL, Goldfarb B, Stelzer HE (2007) Genetic analysis of early field growth of loblolly pine clones and seedlings from the same full-sib families. Can J For Res 37:195205

Baucher M, Halpin C, Petit-Conil M, Boerjan W (2003) Lignin: genetic engineering and impact on pulping. Crit Rev Biochem Mol Biol 38:305-350

Bouffier L, Charlot C, Raffin A, Rozenberg P, Kremer A (2008) Can wood density be efficiently selected at early stage in maritime pine (Pinus pinaster Ait.)? Ann For Sci 65:106-106

Bouffier L, Raffin A, Rozenberg P, Meredieu C, Kremer A (2009) What are the consequences of growth selection on wood density in the French maritime pine breeding programme? Tree Genet Genom 5:11-25 
Burdon RD, Kibblewhite RP, Walker JCF, Megraw RA, Evans R, Cown DJ (2004) Juvenile versus mature wood: a new concept, orthogonal to corewood versus outerwood, with special reference to Pinus radiata and $P$. taeda. For Sci 50:399-415

Burns DA, Ciurczak EW (2008) Handbook of near-infrared analysis, thirdth edn. CRC Press, Boca Raton, p 808 p

Chantre G, Rozenberg P, Baonza V, Macchioni N, Le Turcq A, Petit Conil M, Heois B (2002) Genetic selection within Douglas fir (Pseudotsuga menziesii) in Europe for papermaking uses. Ann For Sci 59:583-593

Chiang VL, Puumala RJ, Takeuchi H, Eckert RE (1988) Comparison of softwood and hardwood kraft pulping. Tappi J 71:173-176

Comstock RE, Kelleher T, Morrow EB (1958) Genetic variation in an asexual species, the garden strawberry. Genetics 43:634-646

Costa e Silva JCE, Wellendorf H, Pereira H (1998) Clonal variation in wood quality and growth in young Sitka spruce (Picea sitchensis (Bong.) Xarr.): estimation of quantitative genetic parameters and index selection for improved pulpwood. Silvae Genet 47:20-33

Costa e Silva J, Borralho NMG, Potts BM (2004) Additive and nonadditive genetic parameters from clonally replicated and seedling progenies of Eucalyptus globulus. Theor Appl Genet 108:11131119

Costa e Silva J, Borralho N, Araújo J, Vaillancourt R, Potts B (2009) Genetic parameters for growth, wood density and pulp yield in Eucalyptus globulus. Tree Genet Genom 5:291-305

Costa P, Durel CE (1996) Time trends in genetic control over height and diameter in maritime pine. Can J For Res 26:1209-1217

Cotterill PP, Dean CA, Van Wyk G (1987) Additive and dominance genetic effects in Pinus pinaster. P. radiata and P. elliottii and some implications for breeding strategy. Silvae Genet 36:221231

Da Silva Perez D, Guillemain A, Chantre G, Alazard P, Alves A, Rodrigues J, Rozenberg P, Plomion C, Robin E (2005) Improvement of wood, pulp and paper quality of maritime pine (Pinus pinaster Ait) by combining rapid assessment techniques and genetics. International symposium on wood, fibre and pulping chemistry. Appita Inc, Auckland, p 207, 214

Da Silva Perez D, Guillemain A, Alazard P, Plomion C, Rozenberg P, Carlos Rodrigues J, Alves A, Chantre G (2007) Improvement of Pinus pinaster Ait elite trees selection by combining near infrared spectroscopy and genetic tools. Holzforschung 61:611-622

Da Silva Perez D, Guillemain A, Petit Conil M (2008) Some factors influencing the prediction of wood and pulp properties by near infrared spectroscopy. O Papel 69:60-75

Danjon F (1994) Heritabilities and genetic correlations for estimated growth curve parameters in maritime pine. Theor Appl Genet 89:911-921

Dumail JF, Castéra P, Morlier P (1998) Hardness and basic density variation in the juvenile wood of maritime pine. Ann For Sci 55:911-923

Falconer DS, Mackay TFC (1996) Introduction to quantitative genetics. Longman, New York

Foster GS, Shaw DV (1988) Using clonal replicates to explore genetic variation in a perennial plant species. Theor Appl Genet 76:788-794

Gaspar MJ, Louzada JL, Silva ME, Aguiar A, Almeida MH (2008) Age trends in genetic parameters of wood density components in 46 half-sibling families of Pinus pinaster. Can J For Res 38:1470-1477

Gaspar MJ, de-Lucas AI, Alia R, Almiro Pinto Paiva J, Hidalgo E, Louzada J, Almeida H, González-Martínez SC (2009) Use of molecular markers for estimating breeding parameters: a case study in a Pinus pinaster Ait. progeny trial. Tree Genet Genom 5:609-616

Gilmour AR, Thompson R, Cullis BR (1995) Average information REML: an efficient algorithm for variance parameter estimation in linear mixed models. Biometrics 51:1440-1450
Gilmour AR, Gogel BJ, Cullis BR, Thompson R (2006) ASReml user guide release 2.0. VSN International Ltd, Hemel Hempstead

Hannrup B, Cahalan C, Chantre G, Grabner M, Karlsson B, Bayon IL, Jones GL, Müller U, Pereira H, Rodrigues JC (2004) Genetic parameters of growth and wood quality traits in Picea abies. Scand J For Res 19:14-29

Henderson CR (1975) Best linear unbiased estimation and prediction under a selection model. Biometrics 31:423-447

Hu WJ, Harding SA, Lung J, Popko JL, Ralph J, Stokke DD, Tsai CJ, Chiang VL (1999) Repression of lignin biosynthesis promotes cellulose accumulation and growth in transgenic trees. Nat Biotechnol 17:808-812

Isik F, Li B, Frampton J (2003) Estimates of additive, dominance and epistatic genetic variances from a clonally replicated test of loblolly pine. For Sci 49:77-88

Jones PD, Schimleck LR, Daniels RF, Clark A, Purnell RC (2008) Comparison of Pinus taeda L. whole-tree wood property calibrations using diffuse reflectance near infrared spectra obtained using a variety of sampling options. Wood Sci Technol 42:385-400

Kube PD, Raymond CA (2002) Prediction of whole-tree basic density and pulp yield using wood core samples in Eucalyptus nitens. Appita J 55:43-48

Kusnandar D, Galwey NW, Hertzler GL, Butcher TB (1998) Age trends in variances and heritabilities for diameter and height in maritime pine (Pinus pinaster Ait.) in Western Australia. Silvae Genet 47:136-141

Leple J-C, Dauwe R, Morreel K, Storme V, Lapierre C, Pollet B, Naumann A, Kang K-Y, Kim H, Ruel K, Lefebvre A, Joseleau J-P, Grima-Pettenati J, De Rycke R, Andersson-Gunneras S, Erban A, Fehrle I, Petit-Conil M, Kopka J, Polle A, Messens E, Sundberg B, Mansfield SD, Ralph J, Pilate G, Boerjan W (2007) Downregulation of cinnamoyl-coenzyme a reductase in poplar: multiple-level phenotyping reveals effects on cell wall polymer metabolism and structure. Plant Cell 19:3669-3691

Martens H, Naes T (1989) Multivariate calibration. Wiley, New York

Mullin TJ, Park YS (1992) Estimating genetic gains from alternative breeding strategies for clonal forestry. Can J For Res 22:14-23

Park YW, Baba K, Furuta Y, Iida I, Sameshima K, Arai M, Hayashi T (2004) Enhancement of growth and cellulose accumulation by overexpression of xyloglucanase in poplar. FEBS Lett 564:183-187

Peter GF, White DE, Torre RDL, Singh R (2007) The value of forest biotechnology: a cost modelling study with loblolly pine and kraft linerboard in the southeastern USA. Int J Biotechnol 9:415-435

Pilate G, Guiney E, Holt K, Petit-Conil M, Lapierre C, Leple JC, Pollet B, Mila I, Webster EA, Marstorp HG, Hopkins DW, Jouanin L, Boerjan W, Schuch W, Cornu D, Halpin C (2002) Field and pulping performances of transgenic trees with altered lignification. Nat Biotechnol 20:607-612

Plomion C, Leprovost G, Stokes A (2001) Wood formation in trees. Plant Physiol 127:1513-1523

Pot D, Chantre G, Rozenberg P, Rodrigues JC, Jones GL, Pereira H, Hannrup B, Cahalan C, Plomion C (2002) Genetic control of pulp and timber properties in maritime pine (Pinus pinaster Ait.). Ann For Sci 59:563-575

Pot D, Rodrigues J-C, Rozenberg P, Chantre G, Tibbits J, Cahalan C, Pichavant F, Plomion C (2006) QTLs and candidate genes for wood properties in maritime pine (Pinus pinaster Ait.). Tree Genet Genom 2:10-24

Puls J, Glawischnig TD, Herrmann A, Borchmann A, Saake B (1995) Comparative investigations for quantitative determinations of wood sugars. In: The 8th International Symposium on Wood and Pulping Chemistry, Helsinki, Finland, pp. 503-510

Rowell RM (2005) Handbook of wood chemistry and wood composites. Taylor \& Francis, New York

Rydholm SA (1965) Pulping processes. Interscience, New York 
Schwanninger M, Hinterstoisser B (2002) Klason lignin: modifications to improve the precision of the standardized determination. Holzforschung 56:161-166

Sewell MM, Davis MF, Tuskan GA, Wheeler NC, Elam CC, Bassoni DL, Neale DB (2002) Identification of QTLs influencing wood property traits in loblolly pine (Pinus taeda L.). II. Chemical wood properties. Theor Appl Genet 104:214 222

So CL, Via BK, Groom LH, Schimleck LR, Shupe TF, Kelley SS, Rials TG (2004) Near infrared spectroscopy in the forest products industry. For Prod J 54:6-16

Sorensen D, Gianola D (2002) Likelihood, Bayesian and MCMC methods in quantitative genetics. Springer, Berlin

Sykes R, Li B, Isik F, Kadla J, Chang HM (2006) Genetic variation and genotype by environment interactions of juvenile wood chemical properties in Pinus taeda L. Ann For Sci 63:897-904

Tsuchikawa S (2007) A review of recent near infrared research for wood and paper. Appl Spectroscop Rev 42:43-71

Voelker SL, Lachenbruch B, Meinzer FC, Jourdes M, Ki C, Patten AM, Davin LB, Lewis NG, Tuskan GA, Gunter L, Decker SR, Selig MJ, Sykes R, Himmel ME, Kitin P, Shevchenko O, Strauss SH (2010) Antisense down-regulation of 4CL expression alters lignification, tree growth, and saccharification potential of fieldgrown poplar. Plant Physiol 154:874-886

Wagner A, Donaldson L, Kim H, Phillips L, Flint H, Steward D, Torr K, Koch G, Schmitt U, Ralph J (2009) Suppression of 4coumarate-CoA ligase in the coniferous gymnosperm Pinus radiata. Plant Physiol 149:370-383

Wallis AFA, Wearne RH, Wright PJ (1996) Analytical characteristics of plantation eucalypt woods relating to kraft pulp yields. Appita J 49:427-432

Wang T, Aitken SN, Rozenberg P, Carlson MR (1999) Selection for height growth and Pilodyn pin penetration in lodgepole pine: effects on growth traits, wood properties, and their relationships. Can J For Res 29:434-445

Workman JJ, Mobvley PR, Kowalski BR, Bro R (1996) Review of chemometrics applied to spectroscopy: 1985-95. Appl Spectroscop Rev 31:73-124

Wu RL (1996) Detecting epistatic genetic variance with a clonally replicated design: models for low vs high-order nonallelic interaction. Theor Appl Genet 93:102-109

Zobel BJ, Sprague JR (1998) Juvenile wood in forest trees. Springer, Berlin

Zobel BJ, Kellison RC, Matthias MF, Hatcher AV (1972) Wood density of the southern pines. North Carolina Agricultural Experiment Station. Tech Bul 208:56 